\title{
MÍDIAS JORNALÍSTICAS E O DEBATE SOBRE EDUCAÇÃO AMBIENTAL, DE PROFESSORES DA REDE DE EDUCAÇÃO BÁSICA DE SERGIPE: CONTRIBUIÇÕES E INTERPRETAÇÕES
}

\author{
Felipe Alan Souza Santos ${ }^{1}$, Jovenildo Cardoso Rodrigues ${ }^{2}$
}

\begin{abstract}
${ }^{1}$ Doutorando do Programa de Pós-Graduação em Geografia (PPGEO/UFPA), participante do Laboratório de Estudo e Pesquisa sobre Habitação e Moradia (LAHAM). E-mail: felipesantosprof@hotmail.com; http://orcid.org/0000-00024931-2481.

${ }^{2}$ Professor do Programa de Pós-Graduação em Geografia (PPGEO/UFPA), líder do Laboratório de Estudos e Pesquisas sobre Habitação e Moradia (LAHAM). E-mail: jovengeo@yahoo.com.br; https://orcid.org/0000-0002-5650-1168.
\end{abstract}

Artigo recebido em 10/08/2020 e aceito em 20/11/2020

\begin{abstract}
RESUMO
O modelo de sociedade atual encontra-se alicerçado em ações voltadas para a dominação da natureza, que utilizam os meios naturais como recursos a serem apropriados pelos seres humanos para o seu bem-estar. Ao mesmo tempo, cresceram, na mídia jornalística, as denúncias de mal governança dos recursos socioambientais. Cogita-se que suas informações estejam sendo apropriadas por profissionais de educação para discutirem, trabalharem, planejarem as problemáticas socioambientais em suas salas de aulas. Desse modo, o presente artigo objetiva discutir possíveis influências da mídia no desenvolvimento do trabalho docente e suas implicações na prática de Educação Ambiental. Metodologicamente, foram feitas leituras de artigos existentes na biblioteca Capes de produção científica. Também foi aplicado um questionário misto a 27 professores de uma escola pública da Grande Aracaju, que foram categorizados segundo Bardin (2011). As informações da mídia contribuem para a inquietação, porém é necessário o aprofundamento teórico e científico do seu debate, pois, em alguns momentos, não existe uma explicação sólida, coerente e coesa dos diferentes fenômenos que envolvem as questões ambientais.
\end{abstract}

Palavras-chave: Professor. Jornalismo. Educação Ambiental.

\section{JOURNALISTIC MEDIA AND THE DEBATE ON ENVIRONMENTAL EDUCATION, BY TEACHERS FROM SERGIPE'S BASIC EDUCATION NETWORK: CONTRIBUTIONS AND INTERPRETATIONS}

\begin{abstract}
The current model of society is based on actions aimed at the domination of nature, which intend to use natural means as resources to be appropriated by human beings for their well-being. At the same time, complaints of poor management of socioenvironmental resources grew in the journalistic media, considering that their understanding is being appropriated by education professionals to discuss, work, plan some of this content in their classrooms. In this way, this article aimed to discuss possible media influences on the development of teaching work and its implications in the practice of Environmental Education. Methodologically, a mixed questionnaire with 27 professors from the institution was applied, which were categorized according to Bardin (2011), in addition to readings of existing articles in the Capes library of scientific production. The information from the media contributes to the restlessness, but it is necessary to deepen the
\end{abstract}


theoretical and scientific aspects of its debate, as at times there is no solid, coherent and cohesive explanation of the different phenomena in which environmental issues are involved.

Keywords: Teacher. Journalism. Environmental Education.

\title{
MEDIOS PERIODISTAS Y EL DEBATE SOBRE EDUCACIÓN AMBIENTAL, POR PROFESORES DE LA RED DE EDUCACIÓN BÁSICA DE SERGIPE: CONTRIBUCIONES E INTERPRETACIONES
}

\begin{abstract}
RESUMEN
El modelo de sociedad actual se basa en acciones orientadas al dominio de la naturaleza, que utilizan los medios naturales como recursos de los que el ser humano se apropia para su bienestar. Al mismo tiempo, crecieron en los medios periodísticos las quejas por la mala gobernanza de los recursos socioambientales. Se piensa que su información está siendo apropiada por los profesionales de la educación para discutir, trabajar, planificar temas socioambientales en sus aulas. Así, este artículo tiene como objetivo discutir las posibles influencias de los medios en el desarrollo de la labor docente y sus implicaciones para la práctica de la Educación Ambiental. Metodológicamente, se realizaron lecturas de artículos de la biblioteca de producción científica de Capes. También se aplicó un cuestionario mixto a 27 profesores de una escuela pública de Grande Aracaju, los cuales fueron categorizados según Bardin (2011). La información de los medios de comunicación contribuye a la preocupación, pero es necesario profundizar el debate teórico y científico, ya que, en ocasiones, no existe una explicación sólida, coherente y cohesionada de los diferentes fenómenos que involucran temas ambientales.
\end{abstract}

Palabras clave: Profesor. Periodismo. Educación ambiental.

\section{INTRODUÇÃO}

A destruição do meio ambiente representa um problema de esfera global, que origina incertezas cada vez maiores por parte daqueles que se preocupam com o futuro da humanidade. Nos últimos tempos, um dos problemas que precisam ser solucionados refere-se à crescente degradação socioambiental, e uma proposta inovadora é promover uma educação que possibilite a busca de uma transformação na sociedade e efetive o entendimento nas pessoas de que suas ações refletem no meio ambiente como um todo. O ramo da educação com esse direcionamento é a Educação Ambiental (EA).

Nessa perspectiva, a Educação Ambiental se torna fundamental na busca de solução para sanar tais preocupações, pois, diante de uma sociedade complexa, as pessoas necessitam agregar novos olhares. Isso pode ser fruto de uma instrução escolar que caminhe com tal objetivo. Então, cabe ao professor a sapiência de mediar as descobertas para que os primeiros conhecimentos sobre a vida e a ciência estimulem a busca de novas atitudes e condutas. Para tanto, o professor deve trilhar caminhos que busquem novas mediações didáticas e metodológicas para despertar nos alunos a consciência crítica, permitindo o transitar de atitudes cidadãs, éticas e humanas. Sabendo disso, é 
importante compreender quais conhecimentos sobre a problemática os docentes dominam e se a mídia, de alguma forma, influencia na aquisição de informações à respeito das questões socioambientais.

A Educação Ambiental, na contemporaneidade, evidencia um caminho norteador na formação da sensibilização do ser humano frente à cidadania ecológica, pois, como afirma Loureiro (2006), a Educação Ambiental é o meio para a construção de valores éticos, culturais e estéticos de atitudes sustentáveis.

O presente artigo surgiu a partir da inquietude em saber como as mídias jornalísticas sergipanas influenciam na percepção dos professores e de que modo esses mediam os seus procedimentos didáticos e metodológicos no tocante à prática de Educação Ambiental, nos seus variados contextos. Compreende-se que esses profissionais são os responsáveis por discutirem e aplicarem propostas ambientais dentro do âmbito escolar.

O presente trabalho tem como objetivo geral discutir possíveis influências da mídia no desenvolvimento do trabalho do professor e em suas implicações na prática de Educação Ambiental de docentes. Metodologicamente para coleta de dados, foi elaborado um questionário pelo Google Formulário, para se entender melhor a relação entre as informações trazidas por reportagens assistidas sobre as questões ambientais e a interferência das mesmas na prática docente de sua disciplina no contexto ambiental. As respostas dos formulários foram tabuladas e discutidas na secção resultados.

\section{EPÍGRAFE AMBIENTAL NA SOCIEDADE DA COMPLEXIDADE}

No contexto atual, a sociedade vive um emaranhado de incertezas quanto à conservação da natureza, fruto do desrespeito das ações do homem no meio ambiente. Entretanto, é com base nessa perspectiva que a Educação Ambiental (EA) surge como uma alternativa viável para que o ser humano possa se sensibilizar, e que suas ações tenham um direcionamento mais correto no meio socioambiental, já que, nos últimos tempos, a sociedade contemporânea vem consumindo, de modo desenfreado, vários recursos naturais planetários, sem medir as consequências dos seus atos.

A Educação Ambiental é mais do que necessária, pois a mesma possibilita ao sujeito refletir de modo local, regional e global sobre os diversos dilemas que assolam a natureza. Ela aprece como uma alternativa viável para a condução de um saber voltado para os valores humanos, sociais e éticos. 
Ela possibilita que o sujeito tenha uma atitude mais autônoma e responsável no meio socioambiental no qual está inserido.

A perspectiva ambiental consiste num modo de ver o mundo, em que se evidenciam as interrelações e a interdependência dos diversos elementos na constituição e manutenção da vida. Em termos de educação, essa perspectiva contribui para evidenciar a necessidade de um trabalho vinculado aos princípios da dignidade do ser humano, da participação, da co-responsabilidade, da solidariedade e da equidade (BRASIL, 2000, p. 19).

Evidentemente, a Educação Ambiental é cenário de uma possibilidade de transformação ativa da realidade e das condições da qualidade de vida, por meio da conscientização vinda da prática social reflexiva. Essa perspectiva deve ser desenvolvida em processos educacionais formal, nãoformal ou informal, tratando de uma emergência da sociedade contemporânea. Nesse sentido, Loureiro (2006) afirma que:

[...] conscientização é obtida com a capacidade crítica permanente de reflexão, diálogo e apropriação de diversos conhecimentos. Esse processo torna-se fundamental para se formar sociedades sustentáveis, ou seja, orientadas para enfrentar os desafios da contemporaneidade, garantindo qualidade de vida para esta e futuras gerações. (p. 58).

Diante disso, a Educação Ambiental deve ser compreendida em seu significado mais amplo, voltada para a formação de pessoas, para o exercício da cidadania, da responsabilidade e do pleno exercício da consciência ecológica. É necessário tornar o sujeito um ser ativo para solucionar os dilemas locais e para questionar os contextos globais (LIMA, 1984, p. 18).

A Educação Ambiental está sendo pautada como um agente de transformação e aprimora a relação dos seres humanos com a natureza. Nesse contexto, um dos seus objetivos centrais é criar e estabelecer uma relação harmoniosa, consciente do equilíbrio dinâmico com a natureza, e possibilitar, por meio de novos conhecimentos, o processo de transformação do atual quadro ambiental do planeta. Santos (2011), em sua pesquisa de Mestrado, salienta:

A educação ambiental deve oportunizar uma mudança rápida do indivíduo em um mundo em evolução. Ela deve ser permanente, geral, expressiva e responsável em preparar o indivíduo para analisar, de modo crítico, os atuais problemas do planeta e propor ações que visem a sua superação. Ao mesmo tempo, deve proporcionar conhecimentos adequados à necessidade de desempenhar uma função produtiva e em proteção ao meio ambiente, sempre caminhando com valores éticos. (p. 24).

A Educação Ambiental necessita tornar o sujeito um ser ativo e questionador para resolver dilemas urgentes e pertinentes quanto aos cuidados com a conservação do meio ambiente. Nesse 
sentido, uma educação que proporciona mecanismos em favor da sensibilização do meio natural deve construir um futuro que busque o "bom senso" das pessoas para com a natureza. Sobretudo, ela deve estimular a participação social na forma de participação política, aberta ao diálogo, visando à relação harmoniosa entre os seres vivos e a natureza.

Vale ressaltar que a Educação Ambiental exige um posicionamento crítico e uma vasta gama de conhecimento produzido a partir da reflexão sobre a realidade vivenciada. Consiste em uma proposta fundamentalmente comunitária e deve corporificar, por meio de uma prática cujo objetivo maior é a promoção da sensibilização e a proteção ambiental

A Educação Ambiental tem como foco a formação de cidadãos ambientalmente comprometidos, estejam em idade escolar ou não. Esses indivíduos necessitam ser preparados para atuar melhor na sociedade, transformando-se em atores que possam reivindicar maior prudência, responsabilidade e participação nas decisões socioambientais. Uma boa prática de Educação Ambiental, portanto, deve conduzir o indivíduo ao conhecimento da problemática ambiental (SANTOS, 2012, p. 40).

Um dos princípios da Educação Ambiental é instigar a transformação do sujeito para promover uma sociedade sustentável. Essencialmente, a Educação Ambiental é uma dimensão educativa constante, pela qual a comunidade tem a tomada de consciência de sua realidade global, do tipo de relações que os homens estabelecem entre si e com a natureza, dos problemas derivados das práticas destruidoras do meio ambiente e de suas causas profundas (PETRAGLIA, 1995, p. 13).

Portanto, a Educação Ambiental tem como objetivo proporcionar uma vivência harmônica entre o homem e a natureza. Que os cidadãos olhem para o futuro com uma visão completamente diferente e benéfica em relação à natureza, contribuindo para a superação dos problemas atuais que cercam a sociedade. Assim, a Educação Ambiental necessita vincular o processo ecológico aos sociais na leitura de mundo, de maneira a intervir na realidade e no modo de existir na natureza, para que todos possam viver harmoniosamente, respeitando e valorizando todos os recursos e seres.

\section{A MÍdIA E SUAS CONTRIBUIÇÕES PARA A PRÁTICA DA EDUCAÇÃO AMBIENTAL}

No contexto atual, a existência de indivíduos responsáveis e conscientes de suas ações vem se tornando cada vez mais categórica e urgente, pois os mesmos assumem papéis indispensáveis na construção e formação de outras pessoas, para que essas possam atuar no meio social de modo crítico 
e exerçam a cidadania. Agir de modo sustentável tornou-se necessário no século XXI, pois as pessoas devem, com urgência, modificar seus antigos hábitos e posicionamentos. Atitudes sustentáveis se fazem necessárias para que as gerações futuras também possam desfrutar da natureza com qualidade e com harmonia com todos os seres vivos.

Nesse sentido, o professor torna-se uma peça chave na construção de uma sociedade mais justa e democrática. Isso porque ele pode proporcionar instrumentos necessários para que os alunos se sintam engajados na luta por um mundo melhor (SANTOS, 2007). Dotar o professor de experiência e habilidade para trabalhar com as questões ambientais tornou-se um caminho viável para se levar a Educação Ambiental para vários âmbitos. Segundo Munhoz (2004), uma das formas de levar Educação Ambiental à comunidade é pela ação direta do professor na sala de aula e em atividades extracurriculares. Através de atividades como leitura, trabalhos escolares, pesquisas de campo, experiências de vida, palestras e debates, os alunos poderão entender os problemas que afetam a comunidade onde vivem; solicitados a refletirem e criticarem as ações de desrespeito ao meio ambiente (GUIDO, 2006).

A prática da Educação Ambiental parte da iniciativa de relacionar a teoria com a prática, e isso deve levar os professores a fazerem parte de uma educação continuada, que facilita a compreensão dos dilemas contemporâneos, contribuindo, assim, para a transformação da realidade por sujeitos críticos e atuantes. Segundo a pesquisa de Santos (2011), muitas das vezes, os professores precisam ensinar o que lhes foi negado. Dessa forma, muitos apenas passam a interpretar os problemas com o meio ambiente a partir das diferentes mídias, em especial, a jornalística televisiva.

A efetiva compreensão das questões socioambientais pelos professores pode oportunizar trabalhar, no âmbito escolar, problemas ambientais locais bem como globais. Para tanto, o professor deve partir da realização de uma prática que proporcione aos alunos o desenvolvimento da cidadania, a percepção de que é possível melhorar e transformar o ambiente e se conscientizarem como participantes da ação e responsáveis pelos resultados concretos a serem alcançados por ações viáveis. Tais resultados podem ser: a construção de hortas; a coleta seletiva do lixo; a importância de reduzir, reciclar e reutilizar "e estimular uma participação mais ativa dos discentes ao convidá-los a olhar criticamente seu cotidiano, almejando estabelecer coletivamente um conjunto determinado de problemas, objetivos e soluções para as questões vivenciadas por esses atores sociais" (SANTOS, 2017, p. 10). Sendo necessário ainda uma crítica ao modelo econômico que segrega e aprisiona a liberdade e negligencia uma política ambiental (HARVEY, 2005). 
A preocupação crescente com as questões ambientais vem intensificando os debates sobre o tema. Desse modo, a exposição na mídia aumentou expressivamente. São observados, na forma de publicidade e propaganda, em jornais e revistas, discursos que almejam clarear sobre os dilemas ambientais. Expressões como "responsabilidade, governança, gestão socioambiental, sustentabilidade, atitudes ambientais" tornaram-se notórias no meio, sendo, portanto, relevantes para a disseminação de informação ambiental.

Alguns documentos fornecem a direção sobre as possíveis contribuições dos meios de comunicação para o desabrochar de informações mais específicas sobre as questões socioambientais. O tratado de Educação Ambiental para sociedades sustentáveis e de responsabilidade global, um dos instrumentos mais importantes para o fomento da Educação Ambiental Crítica, propõe, na Diretriz n. 15 do plano de ação, a necessidade da transformação dos meios de comunicação em instrumentos que corroborem para a conservação dos diversos recursos naturais (SILVA, 2010).

Dessa forma, também a Política Nacional de Educação Ambiental (Lei n. 9795/99) (BRASIL, 1999), em seu Artigo $3^{\circ}$, expressa a necessidade de ampliar holisticamente o debate sobre as questões ambientais. Coloca o processo educativo como campo profícuo e necessário e incumbe aos meios de comunicação de massa a tarefa de colaborarem, de modo ativo e permanente, na disseminação de informações e práticas de Educação Ambiental.

Assim sendo, não se pode negar a importância dos meios de comunicação, em especial, a mídia televisiva para o caráter educativo sobre a questão ambiental, porém diferentes pesquisas, como as levantadas no estudo da arte para este artigo, como as de Guido (2006), Luckman (2007) e Silva (2010), repercutem, em suas conclusões, que, predominantemente, as mídias privilegiam a especulação e o catastrofismo, além de suas bases discursivas apresentarem superficialidade nas informações.

Segundo Cox (2010), o crescimento nesse campo foi marcado não somente pelo surgimento de novas mídias especializadas na questão ambiental, mas, principalmente, pela emergência de uma diversidade de temas e abordagens, e também pelo crescimento da consciência pública acerca da questão ambiental. Sendo assim, é necessário um modelo de comunicação que oportunize a efetivação de uma estratégia pedagógica e didática e que seja fiel à racionalidade do conteúdo, que discuta, com os diversos atores, sobre a real situação do meio ambiente e suas implicações sociais nas esferas local, nacional e global. A comunicação ambiental atua na formação das percepções sobre a natureza e também na educação da opinião pública para a problemática e os valores ambientais. Em seu 
pragmatismo, a comunicação ambiental é um instrumento de mobilização para a resolução de problemas ambientais.

\section{PROCEDIMENTOS METODOLÓGICOS}

Esta pesquisa caracterizou-se como exploratória, pois aborda um tema pouco estudado: possíveis influências da mídia na percepções ambiental de professores de uma escola da Rede Pública Estadual de Sergipe. É enquadrada na metodologia descritiva, pois, esse tipo de pesquisa procura abranger aspectos variados de um contexto social, no caso do presente artigo, os conhecimentos e práticas em Educação Ambiental, de professores. As pesquisas descritivas têm como objetivo primordial a descrição das características de determinada população ou fenômeno ou, então, o estabelecimento de relações entre variáveis e uma de suas características mais significativas está na utilização de técnicas padronizadas de coleta de dados, tais como questionários e observação sistemática (GIL, 2006, p. 43).

Os procedimentos metodológicos seguiram duas etapas, a primeira pesquisa bibliográfica em plataforma de pesquisa da Capes e a segunda aplicação de questionário usando o formulário Google. As pesquisas na plataforma, ocorreram entre os meses de fevereiro e julho de 2020, usando as seguintes palavras para pesquisa: mídia e a discussão ambiental, Educação Ambiental, sociedade e natureza, foram encontradas 16 artigos, porém apenas 05 corroboraram com uma discussão mais próxima do presente artigo.

O questionário do formulário da Google, com questões mistas, foi aplicada no mês de julho de 2020. As respostas foram categorizadas e oportunizaram a elaboração de gráficos e tabelas. As mesmas foram analisadas de acordo com a metodologia de análise de conteúdo descrita por Bardin (2011). A análise permitiu extrair dos participantes pontos específicos de sua percepção ou entendimento sobre o objetivo do artigo, onde foram categorizadas e apresentadas em forma de tabelas, gráficos e discussão. A análise das percepções e do estudo da arte, estão apresentados nas seções "Resultados e discussões" a seguir. 


\section{RESULTADOS E DISCUSSÕES}

É notório o aprimoramento técnico-científico da sociedade contemporânea. Desse modo, também se nota esse aprimoramento nos meios de comunicação, que hoje possuem um poder de propagar informação de maneira mais rápida. As mídias, como a televisão, os jornais e a internet, podem ser consideradas valiosos instrumentos aliados à educação.

A sociedade deposita seus desejos, vontades e aptidões na "escola". Essa, por estar presente e conhecer os diferentes dilemas a serem vencidos pela sociedade, deve trilhar caminhos para uma Educação Ambiental crítica, participativa e comprometida com a emancipação e a formação de partícipes que discutam e entendam as diferentes questões socioambientais.

Os professores, por estarem envolvidos com as práticas escolares, almejam construir um ressignificado de vivência de sua ciência com a experiência já vivida pelo aluno. Santos (2012), em sua pesquisa, expõe que alguns professores possuem dificuldades em trabalharem com a Educação Ambiental e que esses entraves são oriundos da formação carente de disciplinas e debates desse cunho em sua formação acadêmica.

Desse modo, este artigo analisou se as informações transmitidas pela mídia televisiva sergipana influenciam a prática de proposta de Educação Ambiental por professores de uma escola pública da Rede Estadual de Ensino de Sergipe. Esta pesquisa contou com a participação de 27 professores, de diversas áreas de formação: Língua Portuguesa, Língua Inglesa, Língua Espanhola, Artes, História, Química, Física, Matemática, Sociologia, Filosofia, Biologia, Educação Física e Ensino Religioso e geografia. Esses profissionais atuam nos Ensinos Fundamental e Médio, na instituição.

Notou-se que um percentual muito grande de professores, cerca de 78,5\%, assistem os dois principais canais abertos do Estado de Sergipe, que é a TV Atalaia de comunicação e a TV Sergipe (filiada à rede globo), é notório expor que ambas apresentam-se no cenário sergipano, com forte influência política, hoje gerenciada por um ex-governador e sua família. Que permite uma crítica sobre o uso da concessões públicas de rádio e TV para a promoção de uma imagem de transparência perante a sociedade, podendo por trás emaranhasse a uma moeda de troca eleitoreira, que usa de sua influência para o ganho de votos. 
A primeira pergunta do questionário procurou conhecer quais desses profissionais trabalharam ou trabalham com a Educação Ambiental. O Gráfico 1 revela o percentual de professores que afirmaram praticar ações ligadas à Educação Ambiental. Tal resultado pode fortalecer a análise de Santos (2011), que expõe uma lacuna na formação curricular dos professores, acabam vedando a prática de ações socioambientais de educação no ensino formal.

Gráfico 1 - Professores que trabalharam ou trabalham com a Educação Ambiental Trabalhei ou trabalho com Educação Ambiental

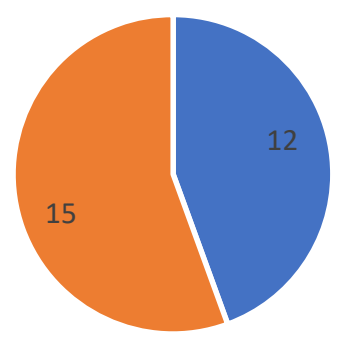

- Sim não

Sobre os possíveis embates para o trabalho com a proposta de Educação Ambiental, os professores colocaram que o maior obstáculo está em conhecer e pensar atividades ligadas a essa prática, reiteram que existe uma lacuna na formação do ensino superior e uma escassez de promoção de cursos de capacitação na rede pública de ensino, que hora não oportunizam a capacitação ou adequação da qualificação profissional e o cotidiano laboral.

Sobre a questão da temporalidade de execução das ações/projetos de Educação Ambiental, pelos professores que afirmaram trabalhar nessa perspectiva, eles colocaram que suas ações eram pontuais, disciplinares e levavam muito em conta a proposta de eventos existente no calendário escolar. Observe as respostas de alguns participantes e os sublinhados nas categorias criadas para análise. 
P 11:Trabalho com alguns temas especificos, como datas comemorativas.

P 17: Não consigo aprofundar uma discussão devido aos diversos conteúdos da grade curricular, não consigo fazer a interdisciplinaridade.

P 27: O tempo, o degaste fisico e emocional, a jornada de trabalho em diferentes escolas contribuem para frear a vontade de apreender a elaborar projetos.

Santos (2011) expõe que a corporificação das atividades de Educação Ambiental nas escolas em datas comemorativas, acabam mais afastando a potencialidade da Educação Ambiental que efetivando espaço dentro das instituições. Pois, grande parte dessas ações acabam sendo realizadas sem um planejamento, negligenciado um objetivo e sem uma observação minuciosa das atitudes e dinâmicas que ocorreram na escola, portanto, para ele, não é dessa maneira que se faz uma Educação Ambiental crítica e cidadã.

Perguntou-se aos professores o que entendiam sobre Educação Ambiental. A Tabela 1 adiante mostra que as categorias mais frequentes estão relacionadas à conscientização das pessoas e à preservação da natureza. Tais categorias mostram uma aproximação conceitual com o tema, apesar de uma quantidade expressiva de professores não trabalharem com a Educação Ambiental. Um número menor de respostas direcionou-se para aspectos mais amplos, tais como o estudo da natureza e o cuidado estrito com a natureza.

Tabela 1 - Conceitos de Educação Ambiental

\begin{tabular}{|c|c|}
\hline CATEGORIAS & $\begin{array}{c}\mathbf{N}^{\mathbf{0}} \text { DE RESPOSTAS } \\
\text { (PERCENTAGEM) }\end{array}$ \\
\hline Conscientização & $20(46,51 \%)$ \\
\hline Preservação & $11(25,58 \%)$ \\
\hline Estudo da natureza & $5(11,63 \%)$ \\
\hline Cuidado estrito com a natureza & $3(6,98 \%)$ \\
\hline Revitalizar o que está prejudicado & $2(4,65 \%)$ \\
\hline Utilização responsável dos & $2(4,65 \%)$ \\
\hline recursos & $43(100 \%)$ \\
\hline TOTAL &
\end{tabular}

*Houve participantes que deram mais de uma resposta.

Exemplos de respostas que ilustram as categorias são apresentados a seguir: 
P10: Educação com foco no meio ambiente, ou seja, que tem como objetivo a conscientização da preservação e utilização de forma responsável dos recursos naturais.

P 07: Educação voltada à prática de conservação da natureza.

P 23: Cuida estritamente do Ambiente.

P 12: Revitalizar o meio ambiente após o mesmo ter sido prejudicado pelo homem.

Observa-se ainda um expressivo distanciamento do homem com a natureza, em algumas categorias apresentadas, duas principais categorias descrita por Santos (2017), a percepção romântica, que compreende a natureza como um bem belo, bonito, inalterado, logo não percebe a influência do homem no processo de transformação. A outra categoria é a pessimista, onde o indivíduo percebe apenas a presença humana e seus níveis de degradação antrópica, portanto, não acredita na mudança de atitude da humanidade frente a sustentabilidade socioambiental.

A categoria conscientização corrobora com o debate de Capra (1996), em que defende o surgimento de um novo paradigma ecológico, no qual o homem deixa de se posicionar como "superior" à natureza. Os resultados mostrados na tabela acima revelam uma aproximação entre a visão de Capra (1996) e os conceitos trazidos por partes dos participantes da pesquisa. Resultados semelhantes a essas categorias foram encontrados na pesquisa de Almeida e Suassuma (2005), que encontraram, entre os estudantes de uma escola pública do Distrito Federal, a percepção de meio ambiente como meio natural em que vivemos.

Leff (2001) expõe que essa mudança de paradigma social dessa aproximação de homem e natureza contribui para reordenar uma transformação das consciências e dos comportamentos dos indivíduos, que atuam em uma nova ordem econômica, política e cultural, de maneira mais crítica, libertadora e transformadora. "Nesse sentido, a educação se converte em um processo estratégico com o propósito de formar os valores, as habilidades e as capacidades para orientar a transição na direção da sustentabilidade.” (LEFF, 2001, p. 12).

Perguntou-se aos participantes se informações transmitidas pelos telejornais sergipanos já tinham sido utilizadas para alguma discussão em sala de aula e se tais informações tinham servido para elaborar ou trabalhar com temas socioambientais em sala de aula. Cerca de 66,66\% dos professores afirmaram já terem usado informações assistidas em telejornais, em suas aulas ou em trabalhos planejados pelos mesmos, e 33,33\% dos participantes afirmaram nunca terem usado informações jornalísticas em sala. 
Esse percentual revela uma forte influência da mídia na prática desses professores, portanto, simbolicamente, se o conteúdo for passado de modo equivocado pela mídia, isso poderá ser repercutido pelos docentes, que não possuem uma aptidão teórica para o debate das questões ambientais. Dessa maneira, os aspectos educativos merecem atenção constante, revelando que a Educação Ambiental pode ser tratada de maneira prescritiva, sem aprofundar os impasses do discurso ecológico (GUIDO, 2006).

A pergunta de número três procurou, junto aos que tinham sido influenciados pelas reportagens jornalísticas, categorizar os conteúdos ou assuntos trabalhados pelos mesmos em sala de aula.

Tabela 2: - Temas trabalhados em sala após intervenção jornalística na área ambiental.

\begin{tabular}{|c|c|}
\hline CATEGORIAS & $\begin{array}{c}\mathbf{N}^{\circ} \text { DE RESPOSTAS } \\
\text { (PERCENTAGEM) }\end{array}$ \\
\hline Recursos hídricos & $25(38,46 \%)$ \\
\hline Aquecimento global & $18(27,69 \%)$ \\
\hline Desmatamento & $14(21,53 \%)$ \\
\hline Recursos naturais & $8(12,30 \%)$ \\
\hline TOTAL & $65(100 \%)$ \\
\hline
\end{tabular}

*Houve participantes que deram mais de uma resposta.

Observa-se uma forte presença de temas ligados à natureza física. Santos (2017) expõe como visão romântica de natureza, em que o homem se vê fora da natureza e passa a romantizar a mesma, inclusive, defende a ideia de que, quando o homem se entender como excluído da natureza, maior será a dificuldade de ocorrer a sensibilização ambiental.

Outro ponto que merece destaque como justificativa para a escolha do tema de trabalho dos professores é o fato de a mídia declarar como ambientais reportagens que discutem problemas com os temas expostos acima. Isso faz com que uma discussão social ou socioambiental seja negligenciada, fazendo-se com que se efetive a ideia de separação entre o homem e a natureza.

Quanto à possibilidade de se conhecer dilemas socioambientais através das informações mediadas pelas redes jornalísticas, obteve-se o seguinte gráfico: 
Gráfico 2 - Confiabilidade em conhecer dilemas socioambientais a partir de reportagens jornalísticas

\section{Possibilidades de conhecer dilemas socioambientais}

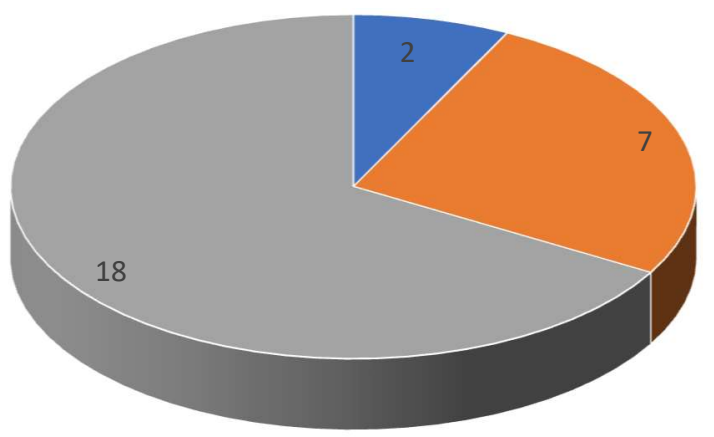

- Sim - Não - Parcialmente

Esse gráfico mostra que, apesar de uma quantidade expressiva de professores $(66,66 \%)$ iniciarem trabalhos de Educação Ambiental a partir de reportagens jornalísticas, esses não confiam apenas na explicação das referidas reportagens. Seguem alguns exemplos de respostas que ilustram essa afirmação:

P 5: Nem todas as redes de televisão e os seus telejornais são livres de alienação.

P 18: Assim como eu, vejo também alguns profissionais (Jornalistas) despreparados.

P 4: Sempre lembro que o jornal também serve para um determinado fim, e a mídia é o domínio das massas.

\section{CONSIDERAÇÕES FINAIS}

A Educação Ambiental tem como princípio contribuir para a construção de uma sociedade mais justa e ecologicamente consciente e equilibrada, e busca uma mudança urgente na atual conduta dos seres humanos e na relação destes com o meio que os cerca. A Educação Ambiental se apresenta como uma nova dimensão a ser incorporada no processo educacional, visto que, mais do que uma realidade, conscientizar e refletir sobre o meio ambiente são necessidades humanas. 
A escola representa um local bastante relevante para a inserção da Educação Ambiental na sociedade, pois, apesar de a sociedade influenciar a escola, esta transborda, em seus muros, o conhecimento formal a ser apreendido pela sociedade. Desse modo, é de suma importância que os docentes gozem de conhecimentos sólidos e pertinentes sobre as questões ambientais. Apenas assim irão se tornar agentes promotores da Educação Ambiental reflexiva, calcada num trabalho contínuo e permanente, objetivando práticas sustentáveis.

As informações da mídia contribuem para a inquietação, porém é necessário o aprofundamento teórico e científico do seu debate, pois, em alguns momentos, não existe uma explicação sólida, coerente e coesa dos diferentes fenômenos. Ainda mais, considerando-se que essas mídias acabam efetivando uma visão romântica da relação homem e natureza, o que acaba aprofundando o abismo de uma educação crítica, inovadora, coletiva e emancipatória.

\section{REFERÊNCIAS}

ALMEIDA, A. J. M.; SUASSUMA, D. A formação da consciência ambiental escolar. Revista eletrônica do Mestrado em Educação Ambiental, v. 15, p. 107-129, 2005.

BARDIN, L. Análise de conteúdo. Lisboa: Edições 70, 2011.

BRASIL, Lei de Diretrizes Curriculares de Educação Ambiental. Lei no 9.795, de 27 de abril de 1999. Brasília.

. Ministério da Educação. Vamos cuidar do Brasil: conceitos e práticas em Educação Ambiental na escola. Brasília: UNESCO, 2007.

Ministério da Educação. Parâmetros Curriculares Nacionais: meio ambiente e saúde/Secretaria de Educação Fundamental. 2. ed. Rio de Janeiro: DP \& A, 2000.

CAPRA, F. O ponto de mutação: uma nova compreensão científica dos sistemas vivos. São Paulo: Cultrix, 1996.

COX, R. Environmental communication and the public sphere. Los Angeles: Sage, 2010.

GUIDO, L. F. E. Educação, televisão e natureza: uma análise do Repórter ECO. Trabalho apresentado no GT 22. Anais da 29 ${ }^{a}$ Reunião Anual da Associação Nacional de Pós-graduação em Educação, Caxambu, 15 a 18 de outubro de 2006.

GIL, A. C. Como elaborar projetos de pesquisa. 4. ed. Reimp. São Paulo: Atlas, 2006.

HARVEY, David. A produção capitalista do espaço. São Paulo: Annablume, 2005.

LEFF, E. Epistemologia Ambiental. Tradução de Sandra Venezuela. Revisão técnica de Paulo Freire Vieira. 4. ed. São Paulo: Cortez, 2001. 
LOUREIRO, C. F. B. O movimento ambientalista e o pensamento crítico: uma abordagem política. 2. ed. Rio de Janeiro: Quartet, 2006.

LUCKMAN, A. P. Educação, jornalismo e meio ambiente: leituras sobre a crise ecológica no contexto do aquecimento global. Anais da 30 ${ }^{\mathrm{a}}$ Reunião Anual da ANPED, GT 16 - Comunicação e Educação, outubro de 2007.

MUNHOZ, Tânia. Desenvolvimento sustentável e educação ambiental. Disponível em: http://rbepold.inep.gov.br/index.php/emaberto/article/view/1805/1776 Acesso em 2004.

PETRAGLIA, Izabel Cristina. Edgar Morin: A educação e a complexidade do ser e do saber. Petrópolis, RJ: Vozes, 1995.

SANTOS, F. A. S. Educação Ambiental: um caminho possível. Redes: Porto Alegre, 2011.

SANTOS, F. A. S. (Org.). Educação, saúde \& meio ambiente: percepções e perspectivas. Porto Alegre: Redes, 2012.

SANTOS, F. A. S. et al. Percepção ambiental e análise de desenhos: prática em curso de extensão universitária. Revista Brasileira de Educação Ambiental, v. 12, n. 2, 2017.

SANTOS, B. S. Para uma revolução democrática da justiça. São Paulo: Cortez, 2007.

SILVA, R. L. F. Leitura de imagens da mídia e educação ambiental: contribuições para a formação de professores. Educ. rev., v. 26, n. 2, Belo Horizonte, Aug. 2010. 